\title{
A Study of Visual acuity among the students in a Rural Girls High School of West Bengal
}

\author{
Dr Kakali Mondal ${ }^{1,}$ Dr Nirmalya Manna $^{1,}$ Dr Urmila Dasgupta ${ }^{1}$ \\ Dr Arup Chakraborty ${ }^{1,}$ Dr Soumi Biswas ${ }^{1,}$ Dr Malay Mundle ${ }^{1}$ \\ ${ }^{1}$ Department of Community Medicine, Medical College, Kolkata, India
}

\begin{abstract}
A hospital based descriptive cross sectional study was conducted in a girls' high school, Tarakeswar, Hooghly, West Bengal to assess the proportion of visual acuity and visual impairment among the students in a Rural High School along with its association with some socio-demographic, environmental and nutritional factors. Out of 160 students, 132 girl students of class VIII, IX, X attended the school on the day of survey. In first step Pre-designed pre-tested self administered questionnaire was filled in by the students. The second step involved eye examination, including students' visual acuity using the Snellen E chart and near vision chart. Data were tabulated in MS EXCEL 2007 and analysed by SPSS 20. Most of the students were Hindu (98.49\%), Poor socio-economic class (63.64\%). Education status of the fathers was mostly primary school completed (36.4\%). $68.9 \%$ students had visual acuity $6 / 6$ and $31.1 \%$ had visual acuity $<6 / 6$ with best available correction in both eyes $(n=132)$. Visual impairment was found in $4.5 \%$ students. The frequency of visual impairment was significantly higher in children with glasses (corrected) as compared to children without glasses (14.3\% versus 4\%). Diet and physical factors had no role with visual acuity.
\end{abstract}

Key Words: visual acuity, visual impairment, high school students

\section{Introduction}

Child's vision is essential for successful learning in school. When the vision suffers, pupil's routine school work and day to day activities also get affected. Vision problems were common among school students. The reasons are mainly unhygienic living conditions, malnourishment and the alluring media influence like television, computer games and diminishing parental care etc. The students are not mature enough to point out the deficiency at the early stage or the parents have no idea on the gradually developing vision problem. This results in tiredness, distraction, headache and a few other disorders. Children who have been affected could not concentrate on studies or on any other curricular, extracurricular or recreational activities. ${ }^{1}$ Treatable refractive error is the major cause $(33.3 \%)$ of the blindness in school children, followed by preventable causes $(16.6 \%)$ like vitamin A deficiency. ${ }^{2}$ The presence of refractive error in school-going students affects their physical, mental and behavioural development as well. ${ }^{3}$ When the vision suffers, routine schoolwork and day to day activities also get affected. ${ }^{4}$ Every five seconds one person in our world goes blind and a child goes blind every minute. 39 million people are blind and 246 million have low vision. 19 million children are visually impaired and 12 million are due to refractive errors. 146 million people with low-vision are due to uncorrected refractive errors which could be restored with eye glasses. $80 \%$ of blindness is avoidable i.e. readily treatable and/or preventable. $90 \%$ of blind people live in low-income countries. ${ }^{5}$ In India, 2011, one out of every three blind people of the world lives. Prevalence of blindness in India is 1.0\% and more among female. 11.75 million blind live in the rural and backward areas. 2.8 million people are blind due to refractive error. 3.2 million children are blind under the age of 16 years. Only $5 \%$ of them receive any education. ${ }^{6}$ According to WHO (ICD-10), visual impairment is the consequence of a functional loss of vision, rather than an eye disorder itself, which is defined as vision of equal to or better than $6 / 18$ in the better eye. Considering the high magnitude of visual impairment in India, the present study was undertaken with the following objectives:

1. To assess the visual acuity and visual impairment among the students in a Rural Girls High school of West Bengal.

2. To identify the socio-demographic, Physical and nutritional factors contributing to visual impairments.

\section{Methodology}

Our study was an observational, descriptive, cross-sectional study. The students of a girls high school situated in Tarakeswar, in the Hooghly district, West Bengal, was determined as the study population. During the screening period, the total number of students of class VIII IX, X attending school was 160, of which 132 $(82.5 \%)$ were examined. However, $17.5 \%$ students (28) did not participate due to their absence from school during the study period. The study period was three months (December to February 2013). A pre-designed pretested semi-structured proforma was filled in by the students. Visual acuity testing was done using the Snellen E 
chart form six meters distance in adequate daylight. The visual impairment cases were determined as a visual acuity of equal to or better than $6 / 18$ in the better eye. A definition of better eye was applied when one eye achieved a better score than the other in the visual acuity examination with the Snellen E charts. During visual acuity examination, the right eye was tested first followed by left eye, with glasses (if glasses present). Age, religion, education of father and PCI (per capita income) were taken as socio-demographic variables. Adequacy of light, duration of study, watching television, use of computer were taken as environmental and diet containing green leafy vegetable \& fresh fruits were taken as nutritional variables. Data were tabulated in MS EXCEL 2007 and analyses by SPSS 20.0 version for frequency, percentages ratios and Chi-square $\left(\chi^{2}\right)$. Ethical permission for the study was obtained prior to data collection from ethics committee of Medical College Kolkata and managing committee and Head mistress of the selected school. Students with visual impairment were referred to Tarakeswar rural hospital for necessary advice.

\section{Results}

Mean age of study population was $14.27 \pm 1.22$ years. Most of the study population was between 14-15 years of age (59.1\%). Majority of the students were Hindu (98.49\%) and from poor socio-economic class (63.64\%). Educational status of the fathers was mostly primary school completed (36.4\%), followed by illiterate $(20.5 \%)$ and post graduate $(3.8 \%)$ (Table $-\mathrm{I})$. Most of the students $(68.9 \%)$ had visual acuity $6 / 6$ whereas $31.1 \%$ had visual acuity $<6 / 6$ with best available correction in both eyes. Visual impairment $(<6 / 12)$ was present among $4.5 \%$ of students. Moderate visual impairment (low vision) was present in $1.5 \%$ student (Table II). The proportion of children with glasses was only $5.3 \%$. The frequency of a presenting visual impairment was significantly higher in children with glasses (corrected) as compared to children without glasses $(14.3 \%$ versus $4 \%)$. Ocular illness was present among $28.03 \%$ of study population $(n=37)$. Pain in eye was complained by most of the study population (51.35\%), followed by headache $48.64 \%$ (Fig II). $62.5 \%$ of study population with visual acuity $6 / 6$ and $37.5 \%$ with visual acuity $<6 / 6$ had taken yellow fruits for $5-7$ days in a week. However no statistically significant relationship was observed between visual acuity and intake of yellow fruits in last 30 days $\left(\mathrm{x}^{2}=2.108, \mathrm{df}=3, \mathrm{p}=0.55\right) .65 .3 \%$ of study population with visual acuity of $6 / 6$ and $34.7 \%$ with visual acuity $<6 / 6$ were taken green leafy vegetable $5-7$ days weekly. $70.8 \%$ students with visual acuity $6 / 6$ and $29.2 \%$ with $<6 / 6$ said adequate light was present in their study room. $68.4 \%$ of study population with visual acuity $6 / 6$ and $31.6 \%$ with visual acuity $<6 / 6$ watched television. Relation between watching T.V and visual acuity was not significant $\left(\mathrm{x}^{2}=0.105, \mathrm{df}=1, \mathrm{p}=0.746\right) .68 .9 \%$ of study population with visual acuity $6 / 6$ and $31.1 \%$ with visual acuity $<6 / 6$ used computer. Relation between use of computer and visual acuity $<6 / 6$ with best available correction was not statistically significant $\left(x^{2}=0.463, \mathrm{df}=2, \mathrm{p}=0.793\right)$.

\section{Discussion}

The present study observed that mean age of the study population was $14.27 \pm 1.22$ years and $1.5 \%$ had low vision. In a study in Nepal (2010) by Marasini S et. al. found that mean age of the students was $10.78 \pm 1.2$ years and low vision was $0.11 \% .{ }^{8}$ In the present study visual impairment was present in $4.5 \%$ of students. In a study by Ghosh $\mathrm{S}$ et. al. among urban school children of low-income families in Kolkata found that visual acuity of less than 6/12 in better eye was present in 4.2\% children. ${ }^{9}$ According to NPCB Survey (2001-02) among children 5-15 years of age, visual impairment was $6.4 \%$ as compared to $4.5 \%$ in present study. In Turkey (2009), Unsal A et. al. found that, mean age of the participants was $10.52 \pm 2.28$ years with a range of 6 to 17 years and visual impairment was $1.7 \% .{ }^{10}$ Best corrected visual acuity of 20/40 and worse in the better eye was $6.4 \%$, and $4.9 \%$ respectively, found by Murthy G.V.S et. al. in New Delhi (2002). In the present study findings were $17 \%$ and $4.5 \%$ respectively. A study on the refractive errors of school going children of Pokhara city in Nepal by Niroula DR and Saha $\mathrm{CG}^{11}$ found that children consuming vegetarian diet had greater number of refractive errors $(10.52 \%)$ than non-vegetarian diet consuming children $(6.17 \%)$. Refractive errors were found significantly higher in Private schools children than Government schools because the children who read in Private schools had higher socioeconomic status; spend more time in home work, watching Television and Computer as compared to government schools children. ${ }^{12}$ However in the present study no statistically significant relationship was found between watching Television and use of computer with visual impairment.

\section{Conclusion}

Screening of the refractive errors in school should be carried out periodically. In addition, school going children and their parents should be educated about signs and symptoms of refractive errors, ocular hygiene and the risk factors involved in the development of refractive errors and other ocular pathological problems. Vision screening of school children in developing countries could be useful in detecting curable causes of vision problems provided detected at the early stage especially refractive errors by which long term visual disability could be avoided. 
VI. Tables and Charts

Table 1: Distribution of study population according their socio demographic profile ( $\mathrm{n}=132)$

\begin{tabular}{|l|c|c|}
\hline Variables & Frequency & Percentages \\
\hline Age in years & 35 & 26.5 \\
$12-13$ & 78 & 59.1 \\
$14-15$ & 19 & 14.4 \\
$16-17$ & & 98.5 \\
Religion & 130 & 1.5 \\
Hindu & 2 & 0.7 \\
Muslim & & 2.3 \\
Socio Economic Status & 1 & 6.1 \\
High (5000-9999) & 3 & 63.6 \\
Upper middle (3000-4999) & 8 & 27.3 \\
Lower middle(1500-2999) & 84 & \\
Poor (500-1499) & 36 & \\
BPL (<500) & & 20.4 \\
Education of the father & & 36.4 \\
Illiterate & 27 & 18.2 \\
Primary school completion & 48 & 9.1 \\
Middle school completion & 24 & 5.3 \\
High school completion & 12 & 6.8 \\
Higher Secondary & 7 & 3.8 \\
Bachelor degree & 9 & \\
Post graduate & 5 & \\
\hline
\end{tabular}

Table 2: Distribution of study population according to visual acuity with best available correction in both eyes $(\mathrm{n}=13$ 2)

\begin{tabular}{|c|cc|cc|}
\hline Visual acuity & Right Eye & Percentage & Frequency & Left Eye \\
\hline $6 / 6$ & 91 & 68.9 & 91 & Percentage \\
$6 / 9$ & 13 & 9.9 & 18 & 68.9 \\
$6 / 12$ & 22 & 16.7 & 18 & 13.7 \\
$6 / 18$ & 4 & 3.0 & 3 & 2.7 \\
$6 / 24$ & 2 & 1.5 & 2 & 1.5 \\
\hline
\end{tabular}

Table 3: Distribution of study population presenting with visual impairment with/without glasses in the better eye

2)

\begin{tabular}{|c|c|c|c|c|}
\hline \multirow{2}{*}{ Glasses } & \multicolumn{2}{|c|}{ Visual acuity $<6 / 12$} & \multicolumn{2}{|c|}{ Visual acuity $\geq 6 / 12$} \\
\hline & Frequency & Percentage & Frequency & Percentage \\
\hline Children with glass (corrected) & 1 & 14.3 & 6 & 85.7 \\
\hline Children without glass & 5 & 4.0 & 120 & 96.0 \\
\hline
\end{tabular}

Table 4: Distribution of study population according to visual acuity and intake of yellow fruits and green leafy vegetables in last 30 days

\begin{tabular}{|l|c|c|c|}
\hline Intake in last 30 days & $\begin{array}{c}\text { Visual acuity } \\
6 / 6\end{array}$ & $\begin{array}{c}\text { Visual acuity } \\
<6 / 6\end{array}$ & Significance \\
\hline Yellow fruit & & & \\
$5-7$ days weekly & $10(62.5)$ & $6(37.5)$ & $16(35.6)$ \\
$3-4$ days weekly & $29(64.4)$ & $13(24.1)$ & \\
$1-2$ days weekly & $41(75.9)$ & $6(35.3)$ & \\
Not taken & $11(64.7)$ & & \\
Green leafy vegetable & & $25(34.7)$ & \\
& $47(65.3)$ & $13(30.3)$ & \\
$5-7$ days weekly & $30(69.7)$ & $3(21.2)$ & 0.55 \\
$3-4$ days weekly & $11(78.8)$ & $0(0)$ & \\
$1-2$ days weekly & $3(100)$ & & \\
Not taken & & & \\
\hline
\end{tabular}

Figures in the parenthesis indicates percentage 
Table 5: Distribution of study population according to visual acuity and physical factors

$(\mathrm{n}=132)$

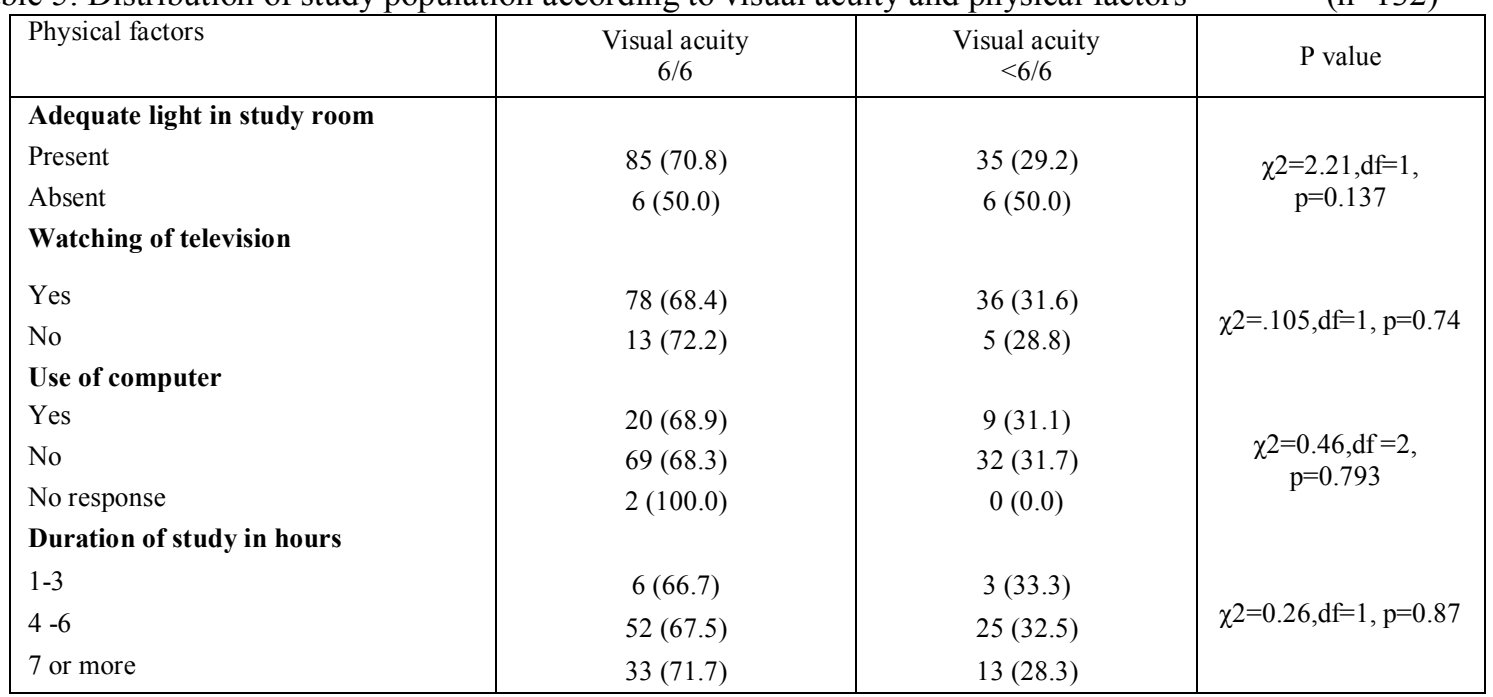

Figures in the parenthesis indicates percentage

Figure 1. Distribution of study population according to visual acuity and presence of ocular illness $(n=132)$

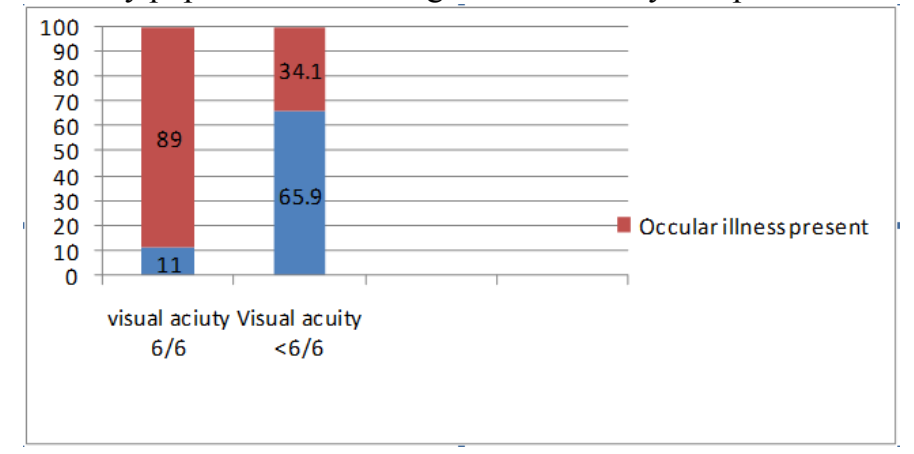

Figure 2: Distribution of the study population according to type of perceived ocular illness (multiple response)

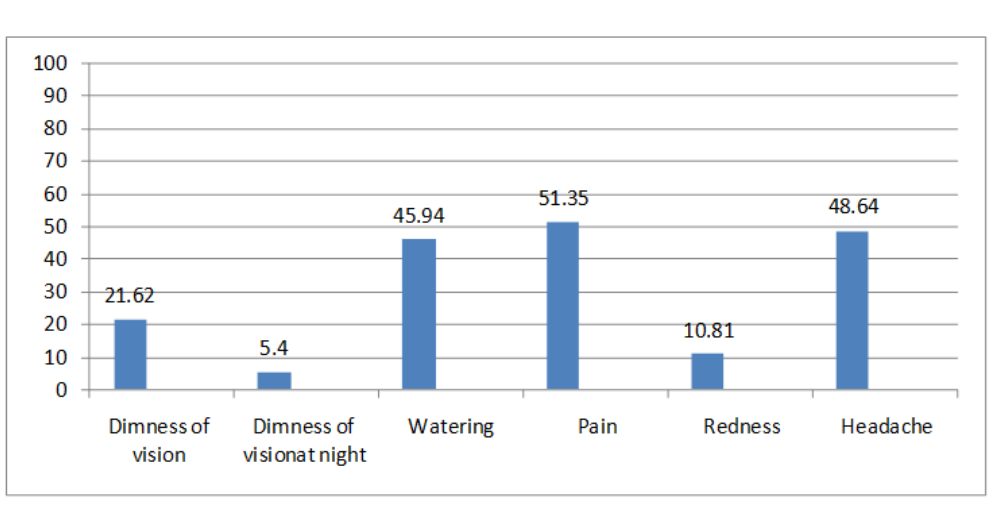

$(n=37)$

\section{References}

[1] Prema .N. Prevalence of refractive error in school children. Indian Journal of Science and Technology. Sep 2011 ;Vol. No. 4 :116061.

[2] Dandona R, Dandona L. Childhood blindness in India: A population based perspective. Br J Ophthalmol 2003;87:263 -5.

[3] Jose R, Sachdeva S. School eye screening and the national program for control of blindness. Indian Pediatr 2009;46:205-8.

[4] Murthy G.V.S, Gupta S K, Ellwein L B, Muñoz S.R, Pokharel G.P ,Sanga L, Bachani D. Refractive Error in Children in an Urban Population in New Delhi. Investigative Ophthalmology \& Visual Science, March 2002; volume no. 43:623-631.

[5] www.who.int/mediacentre/factsheets/fs 282

[6] www.anugrahadrishtidaan.org/Blindness-Global-\&-Indian-Scenario.htm

[7] Visual impairment and blindness In Park.K Parks text book of Preventive and social Medicine $.22^{\text {nd }}$ ed:Bhanot;2013:P.371-2.

[8] Marasini_S, Sharma R, Sthapit PR, Sharma D, Koju U, Thapa G, et al Department of Ophthalmology, Dhulikhel hospital Nepal,Refractive errors and visual anomalies in school children.2010;8(32):632 
[9] Ghosh S, Mukhopadhyay U, Maji D, Bhaduri G. Visual impairment in urban school children of low-income families in Kolkata, India. Indian J Public Health [serial online] 2012 [cited 2013 Feb 10];56:163-7. Available from: http://www.ijph.in/text.asp?2012/56/2/163/99919

[10] Unsal A. Ayranci U, Tozun M.Vision screening among children in primary schools in a district of western Turkey: An epidemiological study: professional medical publications,2009;25(6):976-81.

[11] Niroula DR, Saha CG.Study on the refractive errors of school going children of Pokhara city in Nepal. Kathmandu Univ Med J (KUMJ). 2009 Jan- Mar;7(25):67-72.

[12] Yared A W, Belaynew W T, Destaye S, Ayanaw T, Zelalem E . Prevalence of refractive errors among school children in Gondar town, northwest Ethiopia.Pubmed 2012; Volume : 19 (4): 372-376 